\title{
Research on the Path of College Education Management Innovation from the Perspective of Big Data
}

\author{
Jiao Yang \\ Tianjin University of Finance and Economics, Tianjin, China
}

Keywords: big data; college education management; innovation

\begin{abstract}
With the popularity of the Internet and the rapid development of information technology, the era of big data has come. Big data technology has changed our previous knowledge of data and brought a new perspective to college education management. It has important practical significance for colleges and universities to improve their service quality and management level. This paper analyzes the significance and challenge of big data to college education management innovation, and finally the specific path of big data in college education management innovation is also discussed.
\end{abstract}

\section{Introduction}

With the advent of the era of big data, colleges and universities as places full of intensive knowledge information, dynamic thinking and extensive application of information technology, its degree of informationization in the education management of college students must also be constantly deepened. Colleges and universities should actively introduce big data technology to make it more convenient to acquire and use highly-systematic, classified and structured campus data and so as to make the college education management more scientific, detailed, and individualized. Finally, improve the overall level of college education management and promote development of society.

\section{The Significance of Big Data to College Education Management Innovation}

Big data processing techniques have become the focus of current research. Its combination with college education management is a trend and an inevitable result.

\subsection{Big data innovates college teaching and learning model.}

The teacher was center in traditional teaching mode, which inhibited the students' enthusiasm and initiative, bounded the development of innovative talents. Besides, limited by time, place and other teaching conditions, it's difficult to meet students' individualized teaching needs. But big data breaks through the access to education. Online learning platforms such as MOOC, online curriculum resources, and mobile digital libraries are becoming important ways of learning.

\subsection{Big Data innovates information management in colleges and universities.}

With the of the era of big data coming, the college information management has been further developed. In the university's library system, educational administration system, personnel system, logistics system, security system, and scientific research system, data is recorded at every moment. Using these data efficiently can not only significantly improve the level of college information management, but also promote the management concept more scientific and intelligent.

\subsection{Big data innovates working methods of students' ideological and political education.}

At present, being online has become a state of life for college students. On the one hand, a large amount of data can be generated while college students using the network, which reflects students' ideas, emotions, value orientation and behavioral dynamics. On the other hand, students' ideas and concepts are also affected by various information on the Internet. Colleges and universities can use 
big data technology to innovate work methods, changing their education and management from passive to active and from single to comprehensive, so that they can better ideological and political education of students 。

\section{The Challenges of Big Data in the Innovation of College Education Management}

\subsection{Lack of awareness of using big data}

At present, the application of big data technology in college education management is still in its infancy. The awareness of big data in college administrators is far from universal, and there is insufficient emphasis on the value of big data technology in student management. Besides there are problems in the application, such as insufficient equipment, inconsistent data management model, lack of systematic research and methodology, information security and privacy, which lead to unclear application goals and research directions.

\subsection{Difficulties in data collection and integration}

College education management data is characterized by diverse sources, high value, rich levels, and complex structures. On the one hand, the university's use of big data technology is in its infancy and lacks unified data standards, which may result in repeated collection and increase unnecessary workload. On the other hand, due to the conflicts of interest between the various departments and students, for the sake of information security, there is a disagreement on issue of responsibility for data management and maintenance. Factors above will all challenge the application of big data technology in college.

\subsection{Segmentation of data resources}

Seen from inside, there are great differences in the contents, methods, and priorities of obtaining data and information between different departments of the university, so information management in the internal of universities presents 'isolated data islands' phenomenon. Seen from outside, due to the monopoly of the university on its own data resources, the level of collaborative management between universities is restricted. At the same time, although many universities have established their own data repositories and data centers, they are not unified in terms of standards, which inevitably results in the waste of resources and difficulties of further integration and analysis.

\subsection{Lack of professional and technical personnel}

As far as the current situation is concerned, there are few specialized institutions for big data technology research in universities. Compared with foreign institutions, there is a great gap in research areas, functional orientations and research methods. More importantly, there is a shortage of personnel specialized in computer technology applications, statistical analysis and big data management in many colleges and universities, which also makes it more difficult for colleges to make quick and accurate reactions and judgments.

\section{The Path of Big Data Technology in College Education Management Innovation}

\subsection{Establishing big data service consciousness in college education management}

Establishing a sense of big data services and big data thinking is a prerequisite for promoting the application and deepening of big data technology in universities. For education management in colleges and universities, the first thing to do is to increase the sensitivity to data information. For example, understand and purchase books students prefer through collecting and analyzing information of library catalogs to meet the individual needs of students; Provide timely targeted assistance to those who need help through analyzing consumers' record data ; Provide more practical, accurate and timely employment guidance information for the majority of students through the consolidation and analysis of the information of the recruiter. 


\subsection{Setting up a unified data standard to promote data sharing}

Universities need to establish a unified and standardized data platform and data standard system to integrate and analyze overall data. As far as the interior is concerned, it is necessary to promote the exchange of information among various departments to improve the level of university education management. As far as the outside is concerned, establish university's own student data management center, and strengthen the management and analysis of these data.

\subsection{Breaking the segmentation of data}

On the one hand, we must strengthen the top-level design of big data construction. In order to avoid duplication of construction and inefficient investment, and to further increase input-output ratios, college education management datalization needs to follow the principles of top-level design. On the other hand, it is necessary to break the segmentation of data information and eliminate the 'isolated data island' phenomenon. One of the purposes of building a campus big data system is to realize information sharing, which is an effective way to improve the current situation and is also an important principle through the process of university education management.

\subsection{Introducing professional big data talents}

It is necessary to cultivate and build a professional big data team to command and manage the specific technical links and details in universities. Therefore, colleges and universities must come up with special funds to introduce big data professional and technical personnel, and formulate long-term plans for cultivating big data talents to realize the sustainable development of colleges and universities under the era of big data. At the same time, colleges and universities should continuously strengthen the theoretical research and concrete practice of big data technology in school education management, and speed up the cultivation of big data technology professionals who understand theory, practice and management. Finally, establish a professional big data team to adapt to the development of college education management in the era of 'Internet Plus'.

\section{Conclusions}

The arrival of the era of big data has an inevitable impact on Educational Management in Colleges and universities. And in the future, the mode of education management in Colleges and universities will inevitably take innovation as a way out. Only by innovating in education and management can university education become more powerful. Efficiency also makes it more useful for the society to cultivate talents.

\section{References}

[1] Big Data and analytics in higher education: Opportunities and challenges [J] . Ben Daniel. Br. J. Educ. Technol., 2015 (5)

[2] The Evolution of Big Data and Learning Analytics in American Higher Education. Anthony G Picciano. Journal of Asynchronous Learning Networks. 2012

[3] Massive open online courses, big data, and education research. EICHHORN S, et al. New directions for institutional reserch. 2016

[4] MOOCs as a massive research laboratory: opportunities and challenges [J] . Paul Diver, Ignacio Martinez. Distance Education. 2015 (1)

[5] Global league tables, big data and the international transfer of educational research modalities [J]. Michael Crossley. Comparative Education. 2014 (1) 